\title{
Manufacturing Feasibility Analysis and Load Carrying Capacity of Computer Numerical Control Cut Joints with Interlocking Assembly Feature
}

\begin{abstract}
Mesut Uysal,* Cagatay Tasdemir, Eva Haviarova, and Rado Gazo
The basic manufacturing feasibility and load carrying capacity of computer numerical control (CNC) were evaluated for router-cut joints. More precise and complex shaped geometry was cut on a CNC machine so that joint strength increased via providing a better self-locking system. Using the design for manufacture and assembly (DFMA) analysis, the raw material type and joint design were determined as the main drivers that have direct influence on the processing time and yield of the manufacturing process. Moreover, the bending moment capacity of the joints was determined in compression and tension testing and benchmarked those of rectangular mortise and tenon (RM\&T) and dowel joints. The results showed that joints constructed of plywood performed better than those of medium-density fiberboard according to DFMA compliance score values. Moreover, the load capacity level of joints constructed of plywood provided stronger joints than MDF. In compression tests, CNC router-cut joints constructed of both plywood and MDF reached equal or higher strength relative to traditional joints. Furthermore, in tension tests, those of strength were lower compared to compression test results. The outcome of this study will contribute to the theoretical and practical knowledge of furniture joinery design.
\end{abstract}

Keywords: CNC router-cut joints; DFMA; Manufacturing feasibility; Static load test

Contact Information: Department of Forestry and Natural Resources, Purdue University, 175 Marsteller Street, West Lafayette, IN 47907 USA; *Corresponding author: uysalm@purdue.edu

\section{INTRODUCTION}

The introduction of new technologies into an industry often results in production system changes. Although computer numerical controlled (CNC) technology was initially developed for metalworking, it has become popular for wood processing after the development of special software packages (Tannert et al. 2008). Increased flexibility, ability to cut complex geometric shapes, ability to produce complex three dimensional (3D) structures, a high level of machining accuracy, and the reduction of machine processing steps are some of the benefits of CNC technology (Tannert et al. 2008; Cheng et al. 2015).

Joints are arguably the most vital components in the furniture structure. Furniture failures more often occur due to loose or failed joints rather than fractured legs or rails (Eckelman 2003). Therefore, unreliable joints result in unreliable furniture (Smardzewski 2009). The strength capacity of joints could also rely on the self-locking mechanism, which provides better serviceability and durability performance (Snow et al. 2006; Tamke et al. 2008; Tannert et al. 2008; Simek and Vaclav 2010; Pang et al. 2011). Given the certain level of technological innovations, the nature of the CNC machines is highly suitable to produce 3D complex geometric shapes with increased manufacturing velocity, higher 
accuracy, higher productivity rates, tight tolerances, and lower labor cost (Tannert et al. 2007, 2008; Tamke et al. 2008; Simek and Vaclav 2010). Although CNC manufacturing has many advantages, there are various drawbacks that occur during the manufacturing process due to certain machining conditions, namely processing time, thermal behavior, dynamic response, properties of material being processed (Akturk and Ilhan 2011; Cheng et al. 2015), and the inability to cut and pocket out sharp inner corners. In addition, there are some issues associated with the nature of wood and wood composites, such as grain orientation, corner splitting, or material burning (Tannert et al. 2008). However, the process itself, manufacturing quality, and variation within the process could be controlled if certain guidelines are followed (Kumar et al. 2009). In the literature, various types of CNC router-cut joints were studied for furniture and building constructions (Gros 2001; Davis 2006; Anastas 2007; Simek and Vaclav 2010). However, there is limited information that addresses the simultaneous definition of manufacturing feasibility and strength capacities of these joints.

Given ever-changing industry conditions driven by global trends (Stank et al. 2013), primary focus areas of this study are to determine the basic manufacturing feasibility and load carrying capacity of CNC router-cut joints, namely Dovetail (DT), Mickey Mouse Ear (MME), Blind Mickey Mouse Ear (B-MME), Snap (S), Blind Square Lock (BSL), Puzzle Lock (PL), and Blind Puzzle Lock (B-PL) joints. The manufacturing feasibility of each joint type has been evaluated for the determination of material yield, processing time, as well as design for manufacturing and assembly (DFMA) compliance score (Boothroyd 1994; Boothroyd et al. 2010). Within the scope of strength properties, samples of different joint types were tested for tension and compression. The results of strength tests were benchmarked with comparable traditional joint types- glued dowel, rectangular mortise, and tenon joints.

Determination of whether proposed joint designs could be manufactured has critical importance, because one of the most indispensable factors that add value to any research study is practicality and ability to solve industrial problems. This is the underlying reason why researchers have put extra effort into feasibility analysis. The purpose of a feasibility study is to evaluate and analyze the potential drawbacks and strengths of a proposed project to ease the decision-making process while selecting the CNC joint type. It is a useful tool to reach the optimal form of a production process in terms of manufacturing and cost efficiency (Whitten et al. 2001; Blanchard and Fabrycky 2010; Liu 2015). A feasibility analysis also helps to determine whether the project idea satisfies cost and technological constraints.

Current market trends and increased competitiveness within the industry has forced decision-makers to develop a way to optimize cost-effectiveness of the design process (Boothroyd 1994; Emmatty and Sarmah 2012). Formal developments in the field began towards the late 1970's, although the arrival of systems aiding with assembly time estimation took a couple more years until they were introduced in the early 1980's (Lefever and Wood 1996; Boothroyd et al. 2010; Arnette et al. 2014). Shortly after the introduction of these systems, design for manufacturing (DFM) and design for assembly (DFA) became popular because the concepts were designed to help with cost efficiency by eliminating waste through design and process improvements (Boothroyd 1994; Meeker and Rousmaniere 1996). Within the scope of this study, several quantitative analyses were conducted to test the efficiency of proposed joint types. Both DFM and DFA aim to reduce material and labor costs as a function of optimized product design and manufacturing 
process planning. Therefore, they are often handled together as part of an integrated methodology called DFMA (Ashley 1995; Emmatty and Sarmah 2012; Barbosa and Carvalho 2013). Because the design process accounts for 70 to $80 \%$ of total manufacturing cost, it bears significant importance and deserves discussion (Meeker and Rousmaniere 1996; Bayoumi 2000).

While designing a new product, "the best part is no part" to reach the most efficient form of the process (Boothroyd et al. 2010; Barbosa and Carvalho 2013; Barbosa and Carvalho 2014). However, from the point of view of product strength design, the opposite would apply. Therefore, engineers in cooperation with process and product designers need to come up with the most practical and achievable design while keeping present technology and capital constraints in consideration. In any industry, minimizing the number of parts without compromising product performance is a good way to reduce inventory, which is the key transformation phase into a leaner enterprise (Demeter and Matyusz 2011; Hofer et al. 2012). This study also aims to ensure that proposed joint designs are compatible with the implementation of CNC-type automation.

The results of this study are expected to serve as a guideline for those interested in furniture, joinery design, understanding manufacturing feasibility, and strength properties of different joint types produced by CNC machinery.

\section{EXPERIMENTAL}

\section{Materials and Specimen Construction}

Medium-density fiberboard (MDF) (Menards, West Lafayette, IN, USA) and Baltic Birch plywood (DSA, Indianapolis, IN, USA) board, both widely used materials for furniture and cabinet manufacturing, were picked to prepare both $\mathrm{CNC}$ router-cut and traditional L-shape joint specimens. The mechanical properties of the MDF and plywood are shown in Table 1. Plain white oak (Quercus alba) dowels (Menards, West Lafayette, IN, USA) were used to construct the dowel joints. Polyvinyl acetate adhesive (PVA) (Franklin International, Columbus, IN, USA) at $40 \%$ solids content was used to assemble the joints.

Table 1. Selected Mechanical Properties of Wood Materials Used (Forest Products Laboratory 2010)

\begin{tabular}{|c|c|c|c|}
\hline \multirow{2}{*}{ Material } & \multirow{2}{*}{$\begin{array}{c}\text { Specific } \\
\text { Gravity }\end{array}$} & $\begin{array}{c}\text { Modulus of Elasticity } \\
\text { (GPa) }\end{array}$ & $\begin{array}{c}\text { Modulus of Rupture } \\
\text { (MPa) }\end{array}$ \\
\hline MDF & 0.7 to 0.9 & 3.59 & 35.85 \\
\hline Plywood & 0.4 to 0.6 & 6.96 to 8.55 & 33.72 to 42.61 \\
\hline White Oak & 0.68 & 12.27 & 104.8 \\
\hline
\end{tabular}

The CNC router-cut joints were designed and processed following the joint design process (Fig. 1) by using AutoCAD computer software (Autodesk, v. 2014, Mill Valley, CA, USA), MasterCAM computer software (CNC Software Inc., v. X8, Tolland, CT, USA), and a Thermwood Model 45 CNC router (Thermwood Cooperation, Dale, IN, USA). 


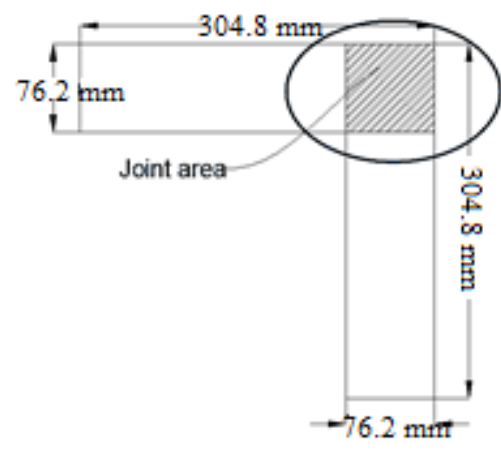

a

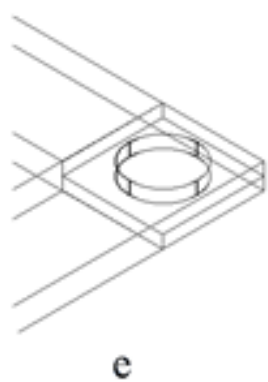

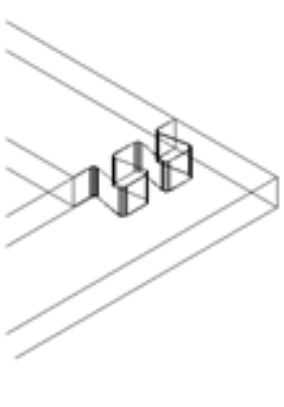

b

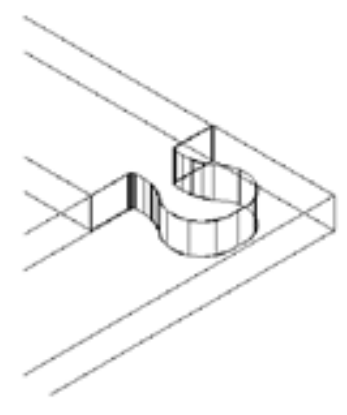

$\mathrm{C}$

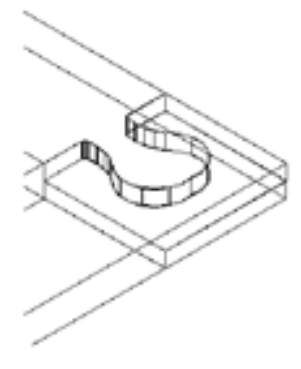

d

Fig. 1. CNC router-cut joints configuration: a: L-shaped joint, b: DT, c: MME, d: B-MME, e: S, f: SL, g: PL, and h: B-PL joints

In designing joints, the design existence in literature was used for DT, S, and SL were designed and developed by the authors, and the designs of PL, B-PL, MME, and BMME were inspired by Gros (2001).

In $\mathrm{CNC}$ router-cutting, specimens were cut in two stages. The first stage utilized a $3 / 8$ bit with cutting $17.75 \mathrm{~mm}$ and $6.35 \mathrm{~mm}$ in z-axes for counters and pockets, respectively. The second stage utilized a $3 / 16$ bit with $1.25 \mathrm{~mm}$ and $3.15 \mathrm{~mm}$ in $\mathrm{z}$-axes for counters and pockets, respectively. In total, $19 \mathrm{~mm}$ for counters and $9.5 \mathrm{~mm}$ for pockets were cut off. More detailed information on the cutting process and parameters is provided in Table 2. Utilizing a $3 / 8$ bit ensured a faster and easier cutting procedure while the $3 / 16$ bit was used to clean the edges and corners, with $0.001-\mathrm{mm}$ tolerances.

Table 2. CNC Machinery Cutting Process

\begin{tabular}{|c|c|c|c|c|}
\hline & $\begin{array}{l}\text { Cutting } \\
\text { Type }\end{array}$ & Material & $\begin{array}{c}3 / 8 \mathrm{bit} \\
(r=4.75 \mathrm{~mm})\end{array}$ & $\begin{array}{c}3 / 16 \mathrm{bit} \\
(r=2.375 \mathrm{~mm})\end{array}$ \\
\hline Spindle Rate & \multirow{3}{*}{-} & \multirow{3}{*}{-} & 18000 rpm & 8149 rpm \\
\hline Feed Rate & & & $350 \mathrm{rpm}$ & $350 \mathrm{rpm}$ \\
\hline Deep Cut & & & $6.35 \mathrm{~mm}$ & - \\
\hline \multirow{4}{*}{ Depth } & \multirow{2}{*}{ Counter } & MDF & $17.78 \mathrm{~mm}$ & $1.27 \mathrm{~mm}$ \\
\hline & & Plywood & $15.24 \mathrm{~mm}$ & $3.05 \mathrm{~mm}$ \\
\hline & \multirow{2}{*}{ Pocket } & MDF & $9.525 \mathrm{~mm}$ & $9.525 \mathrm{~mm}$ \\
\hline & & Plywood & $9.15 \mathrm{~mm}$ & $9.15 \mathrm{~mm}$ \\
\hline
\end{tabular}


During the construction of mortise and tenon joints, tenons 31.25 -mm-long by 50.8mm-wide by 9.4-mm-thick were cut with a multi-chisel machine (Model 101L; Lorraine Machine, Inc., Greenville, SC, USA), as shown in Fig. 2. Matching mortises were cut by a router with $0.001-\mathrm{mm}$ tolerances. The faces of the tenon and the walls of the mortise were coated with a $40 \%$ solid content PVA adhesive and the full length of the tenon was inserted into the mortise and clamped in place (Eckelman et al. 2016).
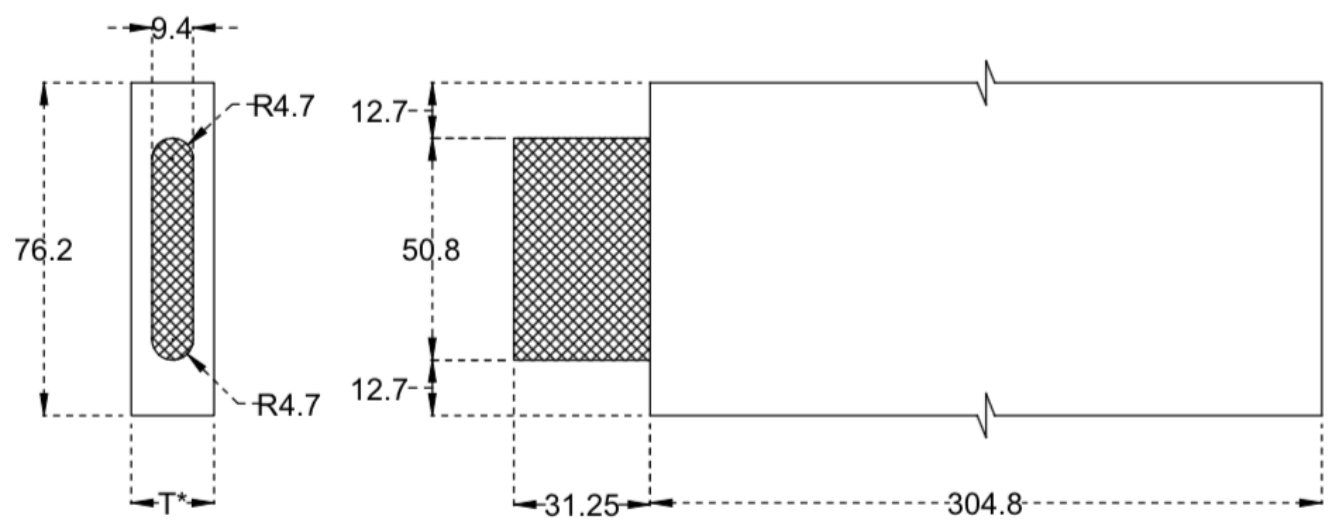

Fig. 2. Rectangular mortise and tenon joint configuration $\left(\mathrm{mm}, \mathrm{T}^{*}\right.$ is $19 \mathrm{~mm}$ for MDF and $18 \mathrm{~mm}$ for plywood)

Plain white oak (Q. alba) dowels with $63.5 \mathrm{~mm}$ length and $9.4 \mathrm{~mm}$ diameter were used to construct the dowel joints. First, 31.25-mm deep dowel holes were drilled on the post and rails by using a multi-chisel machine, as shown in Fig. 3. The wall of drilled holes on posts and the half face of the dowels were generously coated with $40 \%$ solid content PVA adhesive and $31.25 \mathrm{~mm}$ length of the dowel was embedded on the post in the first stage. After at least $8 \mathrm{~h}$ of curing, the wall of drilled holes on the rails and the other half face of dowels embedded on posts were coated with adhesive and the post and rails were assembled (Eckelman et al. 2002). All specimens remained clamped for at least $24 \mathrm{~h}$ in an environment of $7 \%$ moisture content.
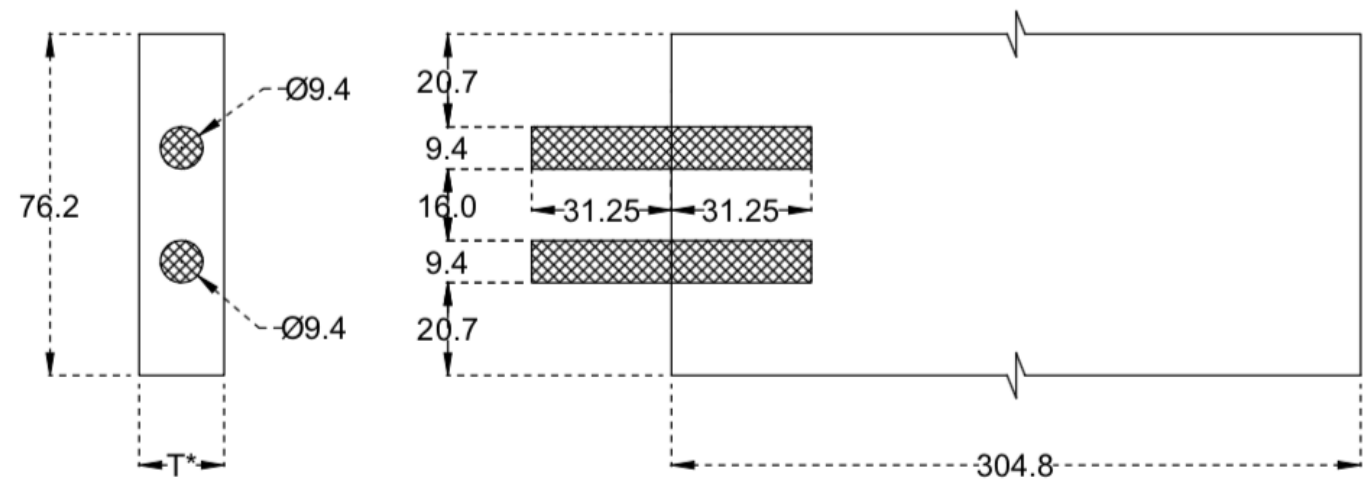

Fig. 3. Dowel joint configuration ( $\mathrm{mm}, \mathrm{T}^{*}$ is $19 \mathrm{~mm}$ for MDF and $18 \mathrm{~mm}$ for plywood)

\section{Methods}

DFMA analysis

A key performance indicator (KPI), called DFMA compliance score was used to determine the DFMA performance of proposed joint types. Each joint type was evaluated 
in terms of two main quantitative criteria, as they were commonly addressed in literature, namely insertion difficulty and handling difficulty (Boothroyd 2005; Boothroyd et al. 2010; Stienstra 2016). The insertion difficulty factor was calculated based on test results performed according to preset guidelines involving insertion time, alignment difficulty, secure fit rate after insertion, and required mechanical assistance during insertion, such as necessity to use a hammer to complete the installation process. The handling difficulty factor was determined as a combined function of handling time, weight, fragility, and flexibility (Kamrani and Nasr 2010). Various results from several analyses were put together on a Microsoft Excel (Microsoft Cooperation, v. Windows 10, Redmond, WA, USA) spreadsheet and were converted into a final grade on a scale from 1 to 10, resulting in a single DFMA performance indicator. The same analyses were independently conducted on plywood and MDF-based joints. However, other feasibility factors and strength properties that were discussed in this study also have crucial importance on general reliability decisions of joint types under investigation.

The guidelines for DFMA were defined under ten main titles in computer-aided manufacturing (Chang et al. 2006). During the entire design phase of proposed joint systems, considerable effort was put into ensuring that all the proposed joint designs conformed with commonly accepted DFMA principles. Therefore, this eliminated interfaces through use of self-locating features with the purpose of achieving a more optimized manufacturing process (Boothroyd 1994; Meeker and Rousmaniere 1996; Barbosa and Carvalho 2014). Final joint designs were determined at the end of detailed discussions and were picked among various alternative designs. It was expected that products with higher DFMA compliance rates would have lower manufacturing, assembly time, and cost. More reliable designs would lead to a high velocity production cycle-time from front-end to back-end throughout the production line.

\section{Processing time and yield calculation}

Manufacturing efficiency of CNC joints was determined by calculating the yield percentages for seven types of $\mathrm{CNC}$ router-cut joints. The $\mathrm{CNC}$ router processing times of the joints were determined to have better understanding of manufacturing feasibility for various joint types. For higher accuracy and reliability, processing times were obtained from MasterCAM 8 software, which was employed to create the design of each joint type, while the yield values were calculated by using the following formulas,

$$
\begin{aligned}
& Y=1-\left(\frac{W_{\mathrm{L}}}{W_{\mathrm{M}}+W_{\mathrm{L}}}\right) \\
& Y_{C}=1-\left[\frac{\left(W_{\mathrm{L}(\text { Arm })}+W_{\mathrm{L}(\text { Post })}\right)}{\left(W_{\mathrm{M}(\text { Arm })}+W_{\mathrm{L}(\text { Arm })}\right)+\left(W_{\mathrm{M}(\text { Post })}+W_{\mathrm{L}(\text { Post })}\right)}\right]
\end{aligned}
$$

where $Y$ is the yield (\%), $W_{\mathrm{L}}$ is the loss to cut $(\mathrm{g}), W_{M}$ is the mean processed material weight (g), $Y_{C}$ is the combined yield (\%), $W_{L(A r m)}$ and $W_{L(P o s t)}$ are the loss (g) to cut in arm and post components, respectively, and $W_{M(A r m)}$ and $W_{M(P o s t)}$ are the initial weight (g) of arm and post components, respectively.

The processing time per board area (PTBA) was used to determine the joint type with the fastest manufacturing time. Because the monetary value of time (Blank and Tarquin 2007) is essential in today's industrial world, faster manufacturing practices are desired and preferred. This parameter is designed to give the total board processing time for a particular joint type as if a complete board was cut to obtain the same type of joint component along the board area. Dimensions of the boards from which the joints were cut 
out were $60 " \times 60 "$ and $48 " \times 96$ " for plywood and MDF, respectively. This metric is appropriate to have a better understanding of manufacturing feasibility of joint types when large-scale production is considered within the scope of leaner manufacturing practices. It is essential to maximize yield and minimize any kind of waste to increase the velocity and efficiency of production systems, which directly contributes towards a pull production system.

\section{Static loading test of joints}

In this study, 90 specimens (70 CNC router-cut and 20 traditional joints) were evaluated to determine the compression and tension load capacity level of different types of L-shape joints cut out of MDF and plywood panels. All of the tests were performed on an MTS test machine (MTS Systems Corp., Eden Prairie, MN, USA) with 1000 N load capacity with a vertical loading rate of $12.7 \mathrm{~mm} / \mathrm{min}$ (Eckelman et al. 2016).

The post of each specimen was mounted on the test jig with bolts. Load was applied on a moment arm of $254 \mathrm{~mm}$ from the face of the post, as seen in Fig. 4 (Erdil et al. 2005).

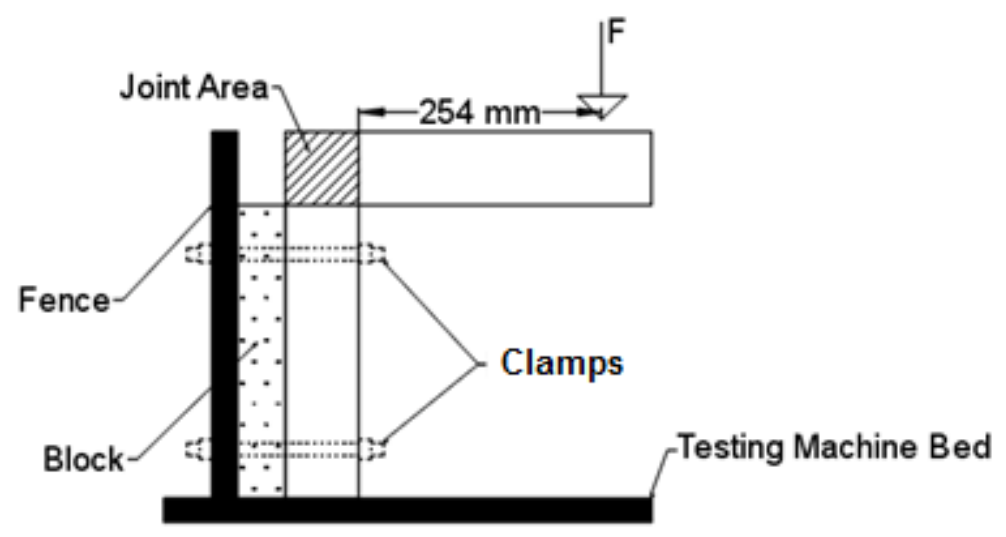

(a)

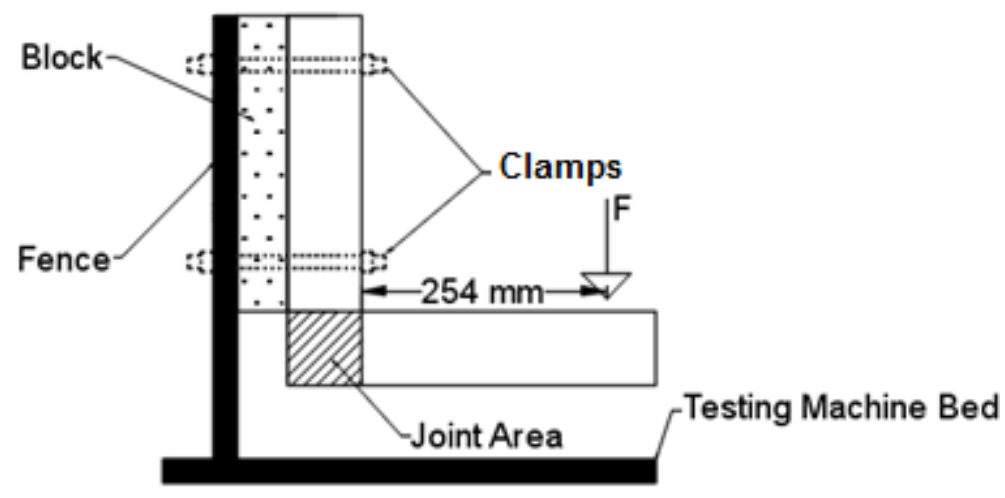

(b)

Fig. 4. Static test configuration: a: compression test and b: tension test

Bending moment capacity $(M$, in $\mathrm{Nm})$ of joints was determined by multiplying the ultimate failure load $(F$, in $\mathrm{N})$ with moment $\operatorname{arm}(L$, in $\mathrm{m})$ :

$$
M=F \times L
$$




\section{RESULTS AND DISCUSSION}

The processing times per board area of the two components for each joint type were not combined. Such a combination would not have produced meaningful results in terms of having a complete understanding of manufacturing velocity and cost efficiency from the perspective of large-scale production. Therefore, PTBA analyses were run independently for each joint member based on the board type. Outcomes of PTBA analysis are expected to ensure that outcomes of this study will contribute to the furniture industry through practical findings.

The overall results of PTBA and total cutting time analysis did not yield drastically different results for joint members made of MDF or plywood, as can be seen in Fig. 5 and Table 3. Within the scope of total cutting time calculations, the CNC cut MDF joints had slightly better cutting velocity performance than their plywood counterparts. Furthermore, joints made of plywood had relatively higher velocity rates in terms of PTBA than those made of MDF, even though by the product structure, plywood is a denser and harder material than MDF.

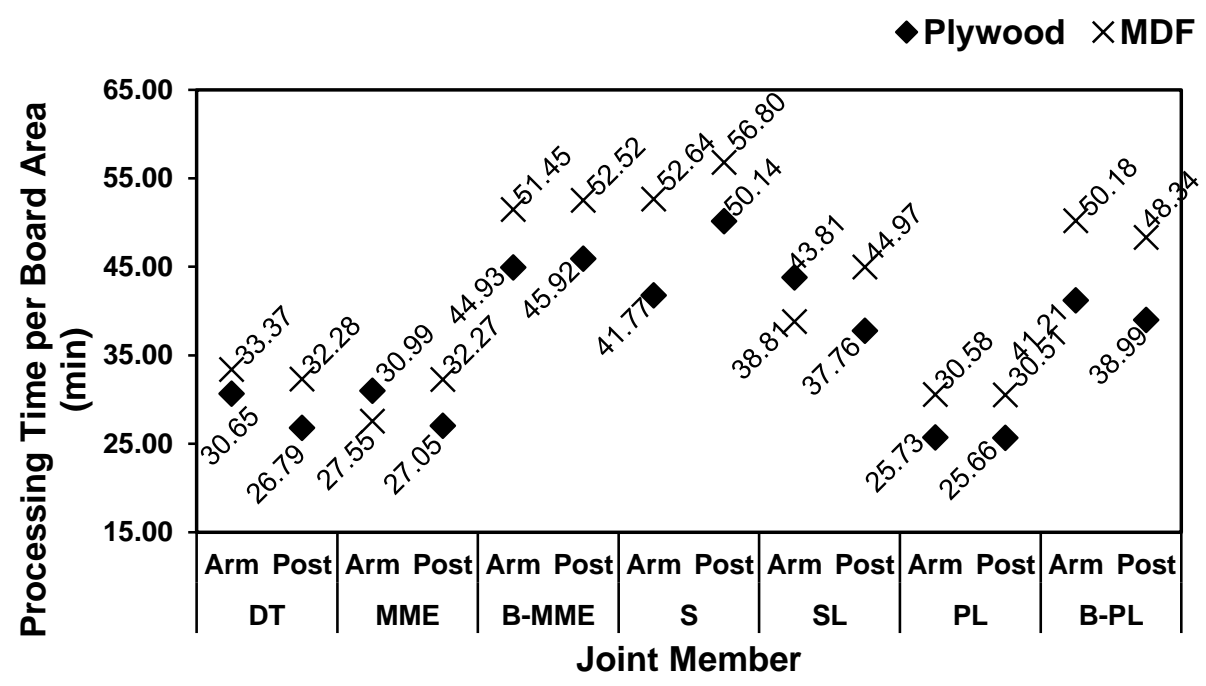

Fig. 5. Processing time per board area for joint members

Arm and post members of PL-type joints had the fastest processing time when compared to other joint types. They were followed by D and MME post members with values of 26.79 and $27.05 \mathrm{~min}$, respectively. Although members of the PL-type joint yielded better PTBA results, low yield performance of the PL-type joint may hinder advantages gained in the means of PTBA. In contrast, PTBA values of DT and MME joint members were accompanied by the highest yield performance rates determined throughout the analysis. Therefore, manufacturing these two types of joints could be more favorable over other options if their strength properties can meet the requirements of certain furniture components. Strength properties of each type of joint was discussed in the related part of the study. Further feasibility interpretations could be made from the results shown in Tables 3 through 6. For instance, to manufacture DT-type joints, which require one MDF board for post and another board for arm members, the cutting process was calculated to take 57.44 min to complete the job, whereas $\mathrm{S}$ joint types required $91.91 \mathrm{~min}$ for the same 
operation. This difference in time was approximately $60 \%$ slower under the same manufacturing conditions and for the same type of board.

Table 3. Total Cutting Time and Processing Time Per Board Area for Joint Members

\begin{tabular}{|c|c|c|c|c|c|c|}
\hline \multirow[b]{2}{*}{$\begin{array}{l}\text { Joint } \\
\text { Type }\end{array}$} & \multirow[b]{2}{*}{ Component } & \multicolumn{4}{|c|}{ Time (s) } & \multirow{2}{*}{$\begin{array}{c}\text { Time (min) } \\
\text { *Processing } \\
\text { Time Per } \\
\text { Board Area }\end{array}$} \\
\hline & & $\begin{array}{c}\text { Bit Type } \\
3 / 8\end{array}$ & $\begin{array}{c}\text { Bit Type } \\
3 / 16\end{array}$ & $\begin{array}{l}\text { Total Time } \\
\text { (Member) }\end{array}$ & $\begin{array}{l}\text { Total Time } \\
\text { (Joint) }\end{array}$ & \\
\hline \multicolumn{7}{|c|}{ Plywood } \\
\hline \multirow{2}{*}{ DT } & Arm & 18.37 & 8.68 & 27.05 & \multirow{2}{*}{58.57} & 30.65 \\
\hline & Post & 21.47 & 10.05 & 31.52 & & 26.79 \\
\hline \multirow{2}{*}{ MME } & Arm & 18.60 & 8.74 & 27.34 & \multirow{2}{*}{59.16} & 30.99 \\
\hline & Post & 21.71 & 10.11 & 31.82 & & 27.05 \\
\hline \multirow{2}{*}{ B-MME } & Arm & 35.92 & 16.94 & 52.86 & \multirow{2}{*}{106.88} & 44.93 \\
\hline & Post & 36.75 & 17.28 & 54.03 & & 45.92 \\
\hline \multirow{2}{*}{ S } & Arm & 31.93 & 17.21 & 49.14 & \multirow{2}{*}{108.13} & 41.77 \\
\hline & Post & 38.77 & 20.22 & 58.99 & & 50.14 \\
\hline \multirow{2}{*}{ SL } & Arm & 26.24 & 12.42 & 38.66 & \multirow{2}{*}{83.08} & 43.81 \\
\hline & Post & 30.11 & 14.31 & 44.42 & & 37.76 \\
\hline \multirow{2}{*}{ PL } & Arm & 20.63 & 9.64 & 30.27 & \multirow{2}{*}{60.46} & 25.73 \\
\hline & Post & 20.57 & 9.62 & 30.19 & & 25.66 \\
\hline \multirow{2}{*}{ B-PL } & Arm & 32.23 & 16.25 & 48.48 & \multirow{2}{*}{94.35} & 41.21 \\
\hline & Post & 30.26 & 15.61 & 45.87 & & 38.99 \\
\hline \multicolumn{7}{|c|}{ MDF } \\
\hline \multirow{2}{*}{ DT } & Arm & 18.79 & 6.88 & 25.67 & \multirow{2}{*}{55.47} & 33.37 \\
\hline & Post & 21.89 & 7.91 & 29.80 & & 32.28 \\
\hline \multirow{2}{*}{ MME } & Arm & 18.50 & 6.93 & 25.43 & \multirow{2}{*}{55.22} & 27.55 \\
\hline & Post & 21.83 & 7.96 & 29.79 & & 32.27 \\
\hline \multirow{2}{*}{ B-MME } & Arm & 27.47 & 20.02 & 47.49 & \multirow{2}{*}{95.97} & 51.45 \\
\hline & Post & 28.75 & 19.73 & 48.48 & & 52.52 \\
\hline \multirow{2}{*}{ S } & Arm & 27.27 & 21.32 & 48.59 & \multirow{2}{*}{101.02} & 52.64 \\
\hline & Post & 28.64 & 23.79 & 52.43 & & 56.80 \\
\hline \multirow{2}{*}{ SL } & Arm & 22.29 & 13.53 & 35.82 & \multirow{2}{*}{77.33} & 38.81 \\
\hline & Post & 26.41 & 15.10 & 41.51 & & 44.97 \\
\hline & Arm & 20.63 & 7.60 & 28.23 & & 30.58 \\
\hline PL & Post & 20.57 & 7.59 & 28.16 & 56.39 & 30.51 \\
\hline PDI & Arm & 26.83 & 19.49 & 46.32 & & 50.18 \\
\hline B-PL & Post & 25.62 & 19.00 & 44.62 & 90.94 & 48.34 \\
\hline
\end{tabular}

As shown in Table 4, the DFMA compliance score of CNC joints did not differ significantly between the two types of materials, namely plywood and MDF. Minor variations were observed for certain types of joints due to lower fragility grades recorded for some MDF joints. In terms of plywood-based joints, PL and B-PL had the highest DFMA fitting scores with grades of 9 , which were followed by DT, MME, and B-MME joint types with grades of 8 . The S-type joint system exhibited the worst DFMA fitting score of 6. In contrast, when DFMA analyses were run on MDF joints, the results were similar to those of their plywood counterparts. When compared to other types of MDF joints, B-PL and PL joint systems had the best DFMA fitting scores, as was the case for 
plywood joint systems. Joints B-PL and PL had DFMA fitting scores of 9 while MME joints scored an 8.

The lowest DFMA performance grade was recorded for S-type joints with a score of 5, followed by SL joint systems that scored a 6 . All of the designs, regardless of the raw material type, successfully satisfied the DFMA requirements for reduced number of parts, modular design, minimized assembly instructions, elimination of separate fasteners, and ease of fabrication. However, some joint types had lower performance results when it came to use of mechanical assistance to complete the insertion process. This is the main reason for the lower DFMA compliance indicator scores of certain types of joints. One explanation was that required mechanical assistance led to fragility problems in some joint types that also had negative impact on DFMA scores. When a cross-evaluation was made on yield and DFMA performance of joints for both material types, it was apparent that joint types with the best DFMA fitting scores were not accompanied with the highest combined average yield values. The results for the cross-evaluation can be seen in Table 4. Therefore, it may be more feasible and efficient to use DT and MME types of joints for large-scale production because they were the ones with the best yield performance and DFMA scores. However, this interpretation may differ based on the results of strength analysis and based on findings of future studies on the subject matter. The impact of strength analysis on such decisions is discussed in the following parts of the study.

As can be seen in Table 4 and Fig. 6, the overall yield performance results followed a similar pattern throughout the seven types of joints for two different material types, namely MDF and plywood. Yield analysis also revealed that MDF joints had relatively better yield performance values than those made of plywood. This may be due to the fact that plywood has a higher density value than MDF. Yield analyses were run based on two different material types used for specimens. Results of yield analyses conducted on joints revealed that DT and MME had the highest average yield values of $78.4 \%$ and $78.3 \%$, respectively, when compared to those of the other 5 types of joints, whereas, PL had the lowest yield performance with $70.3 \%$. The higher yield performance of DT and MME joint types were mainly influenced by high yield percentages of their post members. These two types of joints were followed by SL and B-PL type joints with yield values of $75.1 \%$ and $74.3 \%$, respectively.

Joint members cut out of MDF boards had similar yield performance results with some minor variation in values of average yield and combined average yield performance when compared to plywood counterparts. Joints with the highest yield were DT and MME, at $80.3 \%$ and $77.1 \%$, respectively. They were followed by SL, B-MME, and S with descending values of yield performance by $1 \%$ for all three types of joints. In terms of the lowest yield value, PL and B-PL completed the list at the bottom two rows with yield efficiency rates of $73.6 \%$ and $73.5 \%$, respectively.

Statistical analysis run on SAS (SAS Institute, Cary, NC, USA) and Origin Pro Software (OriginLab Corporation, version 8.6, Northampton, MA USA) generated meaningful results when it comes to the assessment of correlation among dependent variables and factors being evaluated, as seen in Table 5. At the 0.05 significance level, two-way ANOVA results revealed that the population means of material type (MDFplywood) were not significantly different from each other in terms of yield performance for proposed joint types, whereas the population mean of joint types were significantly different and had a P-value of 0.02143 . 
Table 4. Yield Performance and DFMA Compliance Rates of Joint Types

\begin{tabular}{|c|c|c|c|c|c|c|c|}
\hline \multirow[b]{2}{*}{$\begin{array}{l}\text { Joint } \\
\text { Type }\end{array}$} & \multirow[b]{2}{*}{ Part } & \multirow[b]{2}{*}{$\begin{array}{l}\text { Mean } \\
\text { Weight } \\
(g)\end{array}$} & \multicolumn{4}{|c|}{ Yield Calculations } & \multirow[b]{2}{*}{$\begin{array}{c}\text { DFMA } \\
\text { Compliance } \\
\text { Score* }^{\star}\end{array}$} \\
\hline & & & $\begin{array}{l}\text { Average } \\
\text { Loss to } \\
\text { Cut (g) }\end{array}$ & $\begin{array}{l}\text { Combined } \\
\text { Loss to } \\
\text { Cut (g) }\end{array}$ & $\begin{array}{c}\text { Average } \\
\text { Yield } \\
(\%)\end{array}$ & $\begin{array}{l}\text { Combined } \\
\text { Average } \\
\text { Yield (\%) }\end{array}$ & \\
\hline \multicolumn{8}{|c|}{ PLYWOOD } \\
\hline \multirow{2}{*}{ DT } & Arm & 331.62 & 105.11 & \multirow{2}{*}{173.95} & 75.9 & \multirow{2}{*}{78.4} & \multirow{2}{*}{8} \\
\hline & Post & 292.40 & 68.83 & & 80.9 & & \\
\hline \multirow{2}{*}{ MME } & Arm & 318.06 & 118.67 & \multirow{2}{*}{177.22} & 72.8 & \multirow{2}{*}{78.3} & \multirow{2}{*}{8} \\
\hline & Post & 302.69 & 58.54 & & 83.8 & & \\
\hline \multirow{2}{*}{ B-MME } & Arm & 302.62 & 134.11 & \multirow{2}{*}{251.59} & 69.3 & \multirow{2}{*}{71.2} & \multirow{2}{*}{8} \\
\hline & Post & 319.26 & 117.47 & & 73.1 & & \\
\hline \multirow{2}{*}{$\mathbf{S}$} & Arm & 302.52 & 134.21 & \multirow{2}{*}{243.35} & 69.3 & \multirow{2}{*}{72.1} & \multirow{2}{*}{6} \\
\hline & Post & 327.60 & 109.13 & & 75.0 & & \\
\hline \multirow{2}{*}{ SL } & Arm & 319.86 & 116.87 & \multirow{2}{*}{210.75} & 73.2 & \multirow{2}{*}{75.1} & \multirow{2}{*}{7} \\
\hline & Post & 313.79 & 93.87 & & 77.0 & & \\
\hline \multirow{2}{*}{ PL } & Arm & 315.83 & 120.91 & \multirow{2}{*}{259.64} & 72.3 & \multirow{2}{*}{70.3} & 0 \\
\hline & Post & 298.00 & 138.73 & & 68.2 & & $y$ \\
\hline R-PI & Arm & 336.80 & 99.93 & 22461 & 77.1 & 743 & 9 \\
\hline$D-P L$ & Post & 312.06 & 124.67 & $2<4.01$ & 71.5 & 14.3 & $y$ \\
\hline & & & & MDF & & & \\
\hline DT & Arm & 294.28 & 82.23 & 15746 & 78.2 & 803 & 7 \\
\hline DI & Post & 356.37 & 75.23 & $15 \% .40$ & 82.6 & 80.3 & 7 \\
\hline MMF & Arm & 307.44 & 103.67 & 10171 & 74.8 & 771 & 8 \\
\hline DVIVIL & Post & 343.56 & 88.05 & ו ו & 79.6 & 17.1 & 0 \\
\hline R-MMF & Arm & 335.88 & 95.73 & 21392 & 77.8 & & \\
\hline D-IVIVIV & Post & 313.41 & 118.20 & 213.92 & 72.6 & 15.2 & 7 \\
\hline $\mathbf{s}$ & Arm & 337.26 & 94.34 & 21512 & 78.1 & 751 & 5 \\
\hline 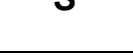 & Post & 310.82 & 120.78 & 210.12 & 72.0 & 10.1 & 3 \\
\hline SL & Arm & 317.76 & 90.15 & 19892 & 77.9 & 763 & 6 \\
\hline & Post & 322.83 & 108.78 & 100.06 & 74.8 & 70.0 & 0 \\
\hline PI & Arm & 315.40 & 116.20 & 23805 & 73.1 & 736 & 9 \\
\hline PL & Post & 319.75 & 111.85 & $2<0.00$ & 74.1 & 13.0 & 9 \\
\hline R-PI & Arm & 300.83 & 130.77 & 20904 & 69.7 & 735 & 0 \\
\hline$D=-T L$ & Post & 333.33 & 98.27 & $\angle \angle 9.04$ & 77.2 & 13.0 & 9 \\
\hline
\end{tabular}

*DFMA compliance score is a combined grade of Insertion Difficulty and Handling Difficulty performances of proposed joint types

It can be concluded that joint type had the largest impact on yield performance of the manufacturing process. In contrast, within the scope of processing time analysis, the population means of both material type and joint type were determined significantly different between the groups at a confidence level of 0.05 , which meant both material type and joint type were important drivers of manufacturing velocity. 


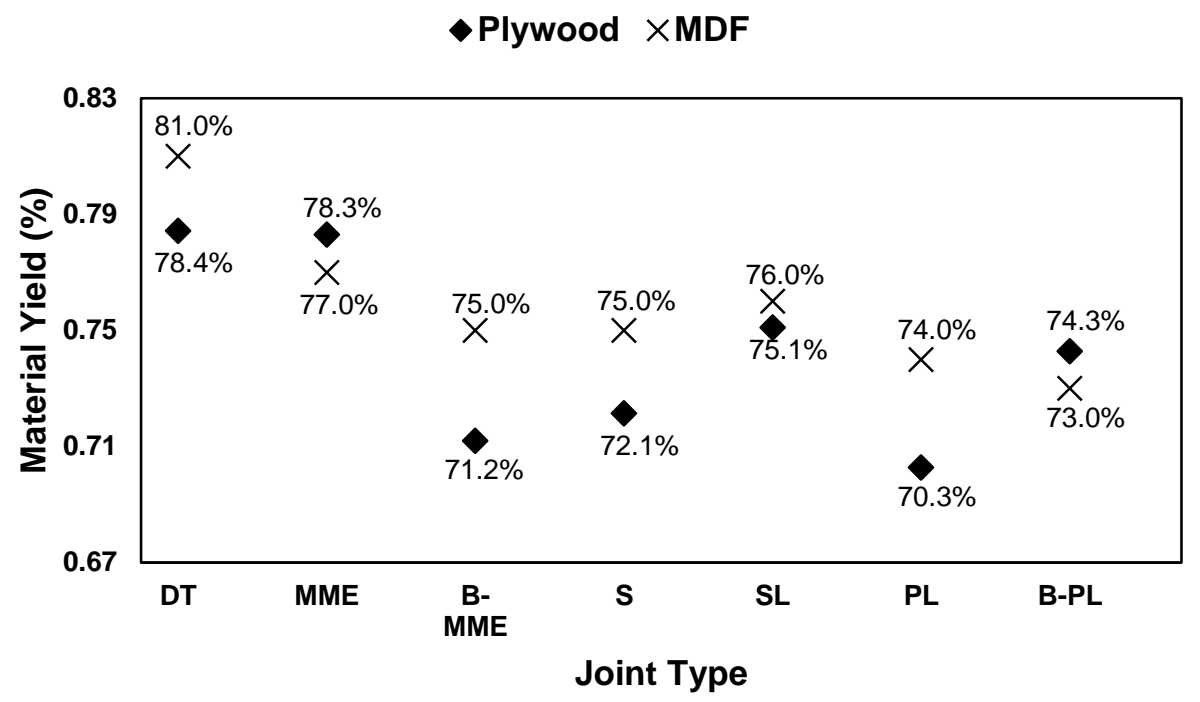

Fig. 6. Yield patterns of proposed joint types based on raw material type

Table 5. Two-Way ANOVA for Assessment of Differences Among Population Means

\begin{tabular}{|c|c|c|c|c|c|}
\hline & DF & $\begin{array}{l}\text { Sum of } \\
\text { Squares }\end{array}$ & $\begin{array}{l}\text { Mean } \\
\text { Square }\end{array}$ & F Value & P Value \\
\hline Material Type & 1 & $9.04 \mathrm{E}-04$ & $9.04 \mathrm{E}-04$ & 3.7168 & 0.10214 \\
\hline Joint Type & 6 & 0.00906 & 0.00151 & 6.2108 & 0.02143 \\
\hline Model & 7 & 0.00996 & 0.00142 & 5.85451 & 0.02341 \\
\hline Error & 6 & 0.00146 & $2.43 \mathrm{E}-04$ & -- & -- \\
\hline Corrected Total & 13 & 0.01142 & -- & -- & -- \\
\hline \multicolumn{6}{|c|}{ ANOVA Analysis: Dependent Variable Yield, at 0.05 Confidence Level } \\
\hline & DF & $\begin{array}{l}\text { Sum of } \\
\text { Squares }\end{array}$ & $\begin{array}{l}\text { Mean } \\
\text { Square }\end{array}$ & F Value & P Value \\
\hline Joint Type & 6 & 5452.79707 & 908.79951 & 234.413 & 7.62E-07 \\
\hline Material Type & 1 & 104.72315 & 104.72315 & 27.0119 & 0.00202 \\
\hline Model & 7 & 5557.52022 & 793.93146 & 204.784 & 1.04E-06 \\
\hline Error & 6 & 23.2615 & 3.87692 & -- & -- \\
\hline Corrected Total & 13 & 5580.78172 & -- & -- & -- \\
\hline \multicolumn{6}{|c|}{ ANOVA Analysis: Dependent Variable Processing Time, at 0.05 Confidence Level } \\
\hline
\end{tabular}

Under current manufacturing conditions and stated technology limitations, it would be crucial to reach an optimal form of joint design for an increased yield and manufacturing velocity performance while material type decision would be considered as a critical factor only when it comes to processing time calculations.

The results of the static loading test of joint specimens are illustrated in Table 6, Fig. 7, and Fig. 8. In the compression static loading test of joints constructed of plywood, PL joints had the highest average bending moment capacity followed by the S joint, B-PL joint, B-MME joint, MME joint, and SL joint, whereas the DT joint had the lowest bending moment capacity. Overall, all CNC router-cut joints had higher average compression bending moment capacities than dowel joints. However, B-MME, S, PL, and B-PL had a higher bending moment capacity level and, MME and SL had roughly close bending moment capacities with RM\&T, whereas only DT had lower bending moment capacity than RM\&T. 
Table 6. Average Bending Moment Capacity in Compression and Tension Test, and Glued Area of Joints

\begin{tabular}{|c|c|c|c|c|c|c|c|c|c|c|}
\hline \multirow{4}{*}{$\begin{array}{c}\text { Joint } \\
\text { Type } \\
\text { DT } \\
\end{array}$} & \multicolumn{5}{|c|}{ Plywood } & \multicolumn{5}{|c|}{ MDF } \\
\hline & \multicolumn{4}{|c|}{ Bending Moment (N.m) } & \multirow{3}{*}{$\begin{array}{c}\begin{array}{c}\text { Glued } \\
\text { Area } \\
\left(\mathbf{c m}^{2}\right)\end{array} \\
34.4 \\
\end{array}$} & \multicolumn{4}{|c|}{ Bending Moment (N.m) } & \multirow{3}{*}{$\begin{array}{c}\begin{array}{c}\text { Glued } \\
\text { Area } \\
\left.\text { (cm }^{2}\right)\end{array} \\
35.8 \\
\end{array}$} \\
\hline & \multicolumn{2}{|c|}{ Compression } & \multicolumn{2}{|c|}{ Tension } & & \multicolumn{2}{|c|}{ Compression } & \multicolumn{2}{|c|}{ Tension } & \\
\hline & 296.9 & (1.6) & 183.9 & $(9.9)$ & & 107.8 & $(7.1)$ & 88.4 & $(6.0)$ & \\
\hline MME & 363.4 & $(9.0)$ & 99.0 & $(8.8)$ & 31.5 & 81.6 & $(5.1)$ & 83.8 & $(4.3)$ & 32.8 \\
\hline B-MME & 449.9 & $(4.0)$ & 315.9 & $(5.7)$ & 55.2 & 132.0 & $(8.5)$ & 122.5 & $(4.4)$ & 55.9 \\
\hline $\mathbf{S}$ & 472.7 & $(15.1)$ & 439.5 & $(11.6)$ & 55.3 & 125.4 & $(5.7)$ & 109.1 & $(8.7)$ & 56.1 \\
\hline SL & 355.7 & (9.9) & 142.1 & $(13.5)$ & 51.9 & 137.6 & $(5.3)$ & 42.7 & $(28.6)$ & 53.2 \\
\hline PL & 483.8 & $(6.3)$ & 125.4 & $(5.7)$ & 50.7 & 214.9 & $(4.1)$ & 84.5 & $(8.0)$ & 52.8 \\
\hline B-PL & 457.6 & $(11.4)$ & 132.9 & $(10.8)$ & 53.7 & 133.1 & (2.6) & 79.8 & $(10.0)$ & 54.6 \\
\hline Dowel & 276.6 & $(18.5)$ & 240.1 & $(14.7)$ & 16.8 & 115.9 & (17.0) & 83.2 & (12.7) & 17.4 \\
\hline RM\&T & 370.6 & (14.3) & 327.7 & (11.9) & 41.1 & 125.4 & (3.2) & 103.0 & (4.8) & 41.7 \\
\hline
\end{tabular}

*Values in parenthesis are the coefficient of variation (COV) of joints (in \%)

As shown in Fig. 7, the compression test results of $\mathrm{CNC}$ router-cut joints constructed of plywood significantly outperformed those of MDF-based joints. Compression values of MDF-based joints varied from one design to another and performed at least $50 \%$ worse than plywood-based joints. For the comparison of the CNC router-cut joints to traditional joints, PL, SL, B-PL, and B-MME had a higher bending moment capacity level than both the RM\&T and dowel, whereas DT and MME had lower bending moment capacities than RM\&T and dowel joints. Moreover, the S joint had the same level of bending moment capacity with RM\&T type joint.

$\diamond$ Plywood $\times$ MDF

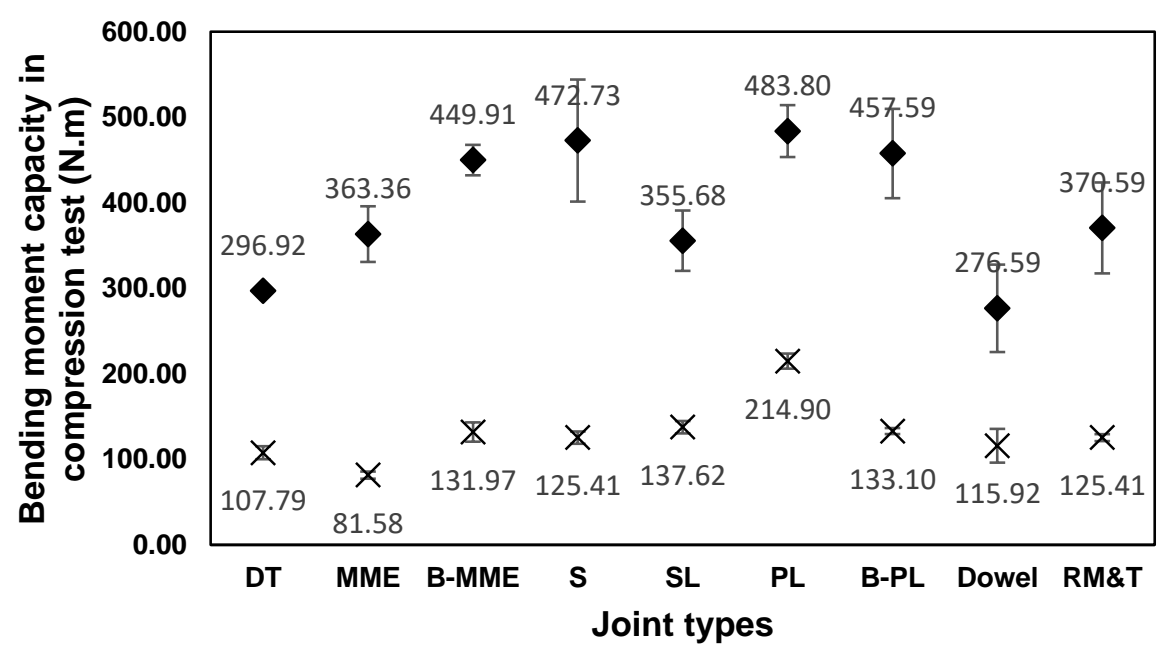

Fig. 7. Bending moment capacity of joints in compression test 
In the tension static loading test of joints constructed of plywood (Fig. 8), the S joint had the highest bending moment capacity followed by B-MME, DT, SL, B-PL, PL, and MME joint. As shown in the same figure, the $S$ joint and B-MME had a higher bending moment capacity level than that of dowel joints, whereas only the $S$ joint had a higher bending moment capacity than the RM\&T based on the results of compression tests. Although MME joints showed better performance in the compression test, they failed earlier because the size of neck in joints was not sufficient in tension.

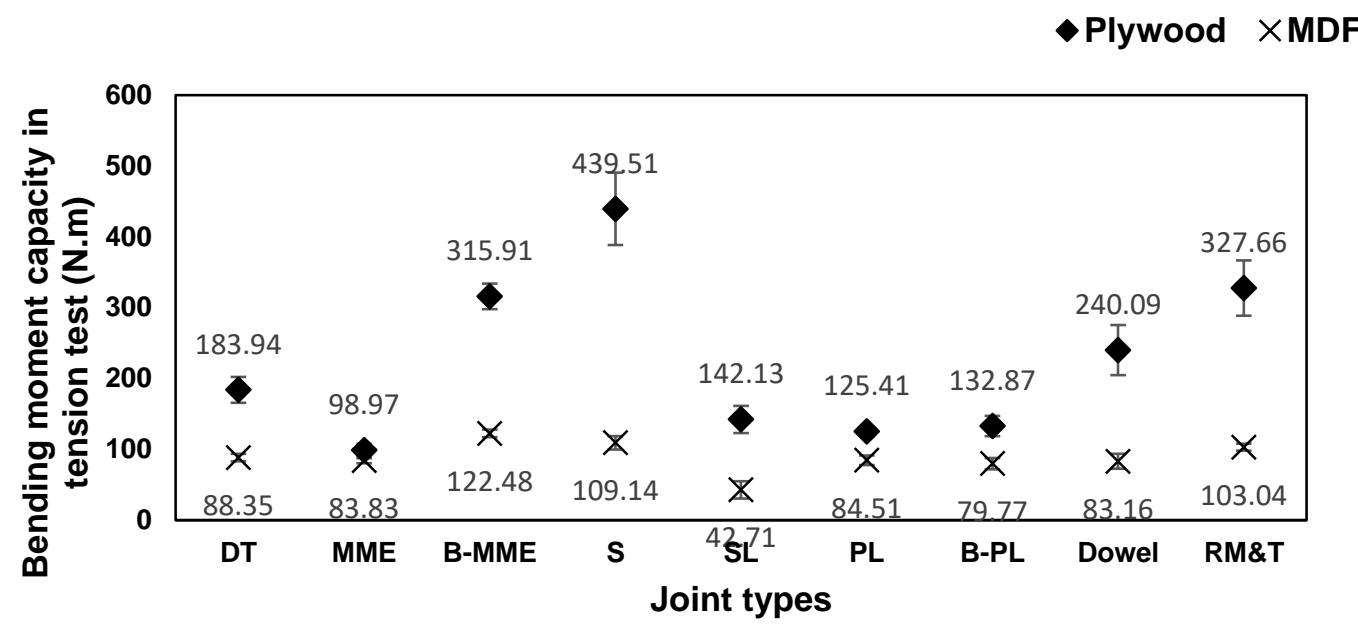

Fig. 8. Bending moment capacity of joints in tension test

Within the scope of the tension static loading test of joints constructed of MDF (Fig. 8), B-MME and S had higher bending moment capacities than the RM\&T-type joint while B-PL and SL had a lower bending moment capacity level than traditional joints. The joint types that had better performance than the dowel joint type were B-MME, S, DT, PL, and MME.

Overall, the test results revealed that joints constructed of plywood had higher load capacity levels in both the compression and tension tests than those of MDF joints. Although joint geometry, adhesive type, manufacturing, and testing procedures were identical for both wood-based materials, the internal bonding strength of panels were different. The internal bonding strength of 38 -mm-thick MDF was $0.51 \pm 0.19 \mathrm{MPa}$ (Rathke et al. 2012), while the internal bonding strength of the 9-mm-thick MDF and plywood was $0.57 \mathrm{MPa}$ and 1.27 MPa, respectively (Suzuki and Miyagawa 2003). Therefore, failure of joints constructed of MDF occurred at lower load capacity levels than those of plywood. Furthermore, in both compression and tension test, the $\mathrm{S}$ joints made of plywood had higher standard deviation which could be due to S joints' weaker self-locking property compared to other joint types (Figs. 7 and 8). Underlying reason of such a wider variation in strength values of $S$ joints could be due to increased prominence of certain failure types namely, shear on glueline and neck of snap. Furthermore, when results for its counterparts made of MDF are checked, this could also be interpreted as; S type joint design may not be the best option where plywood is preferred raw material for manufacturing. However, as given in Table 6, COV values in compression and tension tests for $\mathrm{S}$ type joints were $15.1 \%$ and $11.6 \%$, respectively, and both were comparable to some of other joint types namely, B-PL, Dowel, and RM\&T. 
Both the plywood and MDF PL and B-PL joints had higher bending moment capacity levels in compression tests and lower bending moment capacity levels in tension tests than those of traditional joints. A self-locking characteristic provided the joints with more strength in the compression test. Even though they had more complex geometry, they could not provide higher strength than traditional joints due to the weakness of the selflocking characteristic in tension.

Table 7. Two-way ANOVA for Compression and Tension Test of Joints

\begin{tabular}{|c|c|c|c|}
\hline & F-Value & P-Value & $\mathbf{R}^{\mathbf{2}}$ \\
\hline \multicolumn{3}{|c|}{ Compression Test } \\
\hline Compression test & 109.86 & $<0.0001$ & 0.963 \\
\hline Material type & 1571.81 & $<0.0001$ & 0.810 \\
\hline Joint type & 26.59 & $<0.0001$ & 0.110 \\
\hline Material*joint & 10.39 & $<0.0001$ & 0.043 \\
\hline \multicolumn{3}{|c|}{ Tension Test } \\
\hline Tension test & 146.36 & $<0.0001$ & 0.971 \\
\hline Material type & 1046.93 & $<0.0001$ & 0.409 \\
\hline Joint type & 113.46 & $<0.0001$ & 0.355 \\
\hline Material*joint & 66.7 & $<0.0001$ & 0.208 \\
\hline
\end{tabular}

As can be seen in Table 7, a two-way ANOVA was conducted to evaluate the significance of material type and joint type on the strength properties of joints for bending moment capacity in compression and tension tests. Within the scope of the compression test, the material type, joint type, and combined effect of both the material type and joint type were determined significant at the 0.05 significance level. Variation in joint strength can be explained by the material type, joint type, and interaction of material, respectively by, $81 \%, 11 \%$, and $4.3 \%$. In tension tests, the material type, joint type, and material were significant at the 0.05 significance level. Moreover, the material type, joint type, and interaction of the material and joint type were responsible for $40.9 \%, 35.5 \%$, and $20.8 \%$ of variation in tension test results of joints, respectively.

Bonferroni groupings were run to examine the differences among the proposed joint types in terms of variation in strength properties as shown in Tables 8 and 9. Based on the grouping results, the mean of the joint strength represented with same letter were not significantly different from each other at a 0.05 significance level. In the compression test, for joints constructed of plywood the PL and S joints were significantly different from the RM\&T joint while the PL, S, and BPL joints were significantly different from the dowel joint. For the tension testing, only the B-MME joint was not significantly different from the RM\&T joint while only DT was not significantly different from the dowel joint. For the joints constructed of MDF in compression testing, the PL and MME joints were significantly different from the RM\&T joints whereas the PL, SL, and MME joints were significantly different from the dowel joint. For those of the tension tests, the S and DT joints were not significantly different from the RM\&T as the B-MME, S, and SL joints were significantly different from the dowel joint. 
Table 8. Bonferroni Grouping Test for Joints Constructed of Plywood

\begin{tabular}{|c|c|c|c|c|c|c|c|c|c|c|c|}
\hline \multicolumn{5}{|c|}{ Compression Test } & \multicolumn{5}{c|}{ Tension Test } \\
\hline $\begin{array}{c}\text { Bon } \\
\text { Grouping }\end{array}$ & Mean & N & Joint & & $\begin{array}{c}\text { Bon } \\
\text { Grouping }\end{array}$ & Mean & N & Joint \\
\hline & A & 483.8 & 5 & PL & & & A & 439.5 & 5 & S \\
\hline & A & 472.7 & 5 & S & & & B & 327.7 & 5 & RM\&T \\
\hline B & A & & 457.6 & 5 & B-PL & & B & 315.9 & 5 & B-MME \\
\hline B & A & C & 449.9 & 5 & B-MME & & C & 240.1 & 5 & Dowel \\
\hline B & D & C & 370.6 & 5 & RM\&T & & D & C & 183.9 & 5 & DT \\
\hline B & D & C & 363.4 & 5 & MME & & D & E & 142.1 & 5 & SL \\
\hline & D & C & 355.7 & 5 & SL & & D & E & 132.9 & 5 & B-PL \\
\hline & D & & 296.9 & 5 & DT & & D & E & 125.4 & 5 & PL \\
\hline & D & & 276.6 & 5 & Dowel & & E & 99.0 & 5 & MME \\
\hline
\end{tabular}

Table 9. Bonferroni Grouping Test for Joints Constructed of MDF

\begin{tabular}{|c|c|c|c|c|c|c|c|c|c|c|}
\hline \multicolumn{6}{|c|}{ Compression Test } & \multicolumn{5}{|c|}{ Tension Test } \\
\hline \multicolumn{3}{|c|}{ Bon Grouping } & \multirow{2}{*}{$\begin{array}{l}\text { Mean } \\
214.9\end{array}$} & \multirow{2}{*}{$\begin{array}{l}\mathbf{N} \\
5\end{array}$} & \multirow{2}{*}{$\begin{array}{c}\text { Joint } \\
\text { PL }\end{array}$} & \multicolumn{2}{|c|}{ Bon Grouping } & \multirow{2}{*}{$\begin{array}{l}\text { Mean } \\
122.5\end{array}$} & \multirow{2}{*}{$\frac{N}{5}$} & \multirow{2}{*}{$\frac{\text { Joint }}{\text { B-MME }}$} \\
\hline & A & & & & & & A & & & \\
\hline & $B$ & & 137.6 & 5 & SL & $B$ & A & 109.1 & 5 & $S$ \\
\hline C & $B$ & & 133.1 & 5 & B-PL & $B$ & $C$ & 103.0 & 5 & $\mathrm{RM} \& \mathrm{~T}$ \\
\hline C & $B$ & & 132.0 & 5 & B-MME & $\mathrm{D}$ & $\mathrm{C}$ & 88.4 & 5 & DT \\
\hline C & $B$ & $D$ & 125.4 & 5 & $S$ & $\mathrm{D}$ & & 84.5 & 5 & PL \\
\hline C & B & D & 125.4 & 5 & $\mathrm{RM} \& \mathrm{~T}$ & $\mathrm{D}$ & & 83.8 & 5 & MME \\
\hline \multirow[t]{3}{*}{$\mathrm{C}$} & & D & 115.9 & 5 & Dowel & $\mathrm{D}$ & & 83.2 & 5 & Dowel \\
\hline & & $\mathrm{D}$ & 107.8 & 5 & DT & $\mathrm{D}$ & & 79.8 & 5 & B-PL \\
\hline & $E$ & & 81.6 & 5 & MME & & $E$ & 42.7 & 5 & SL \\
\hline
\end{tabular}

Another two-way ANOVA was conducted to evaluate the relationship between $\mathrm{CNC}$ router-cut joint strength and glue area (or joint interaction area). The results of this analysis indicated that the relationship between the joint strength and glue area was significant at a 0.05 confidence level, as shown in Table 10.

Table 10. Two-way ANOVA Analysis for Strength and Glue Area Relationship for CNC Router-cut Joints

\begin{tabular}{|c|c|c|c|c|}
\hline Material Type & Type of Test & F-value & P-value & $\mathbf{R}^{\mathbf{2}}$ \\
\hline \multirow{2}{*}{ Plywood } & Compression & 15.96 & $<0.0001$ & 0.773 \\
\cline { 2 - 5 } & Tension & 138.79 & $<0.0001$ & 0.967 \\
\hline \multirow{2}{*}{ MDF } & Compression & 148.02 & $<0.0001$ & 0.969 \\
\cline { 2 - 5 } & Tension & 146.36 & $<0.0001$ & 0.971 \\
\hline
\end{tabular}




\section{Future Work}

Providing a better self-locking characteristic for CNC Router-cut joints in tension tests could be concern for future study. Moreover, conducting future DFX studies that address different aspects of engineering design and measure the impact of different types of glues on the strength properties of proposed joint types would contribute greatly to the literature of wooden furniture joints.

\section{CONCLUSIONS}

This paper aimed to determine the basic manufacturing feasibility and load carrying capacity of L-shape CNC router-cut joints. Assembly and manufacturing feasibility of joint designs was examined through design for manufacture and assembly (DFMA) analysis, while the load capacity tests evaluated whether the proposed joint types comply with certain strength requirements critical for the furniture industry. Within the scope of this study, theoretical arguments were supported with practical applications and statistical analysis to provide readers with a full understanding of the design and manufacturing processes related to certain joint types, as well as to document strength properties of proposed joint types under certain conditions. Research questions related to feasibility and strength design concepts were answered through a systematic methodology and valuable results were obtained.

1. Through DFMA studies, it was found that most of the proposed joint types could be manufactured in an industrial setting. However, it was also found that some proposed joint types could generate less efficient performance results depending on raw material type and joint design, correspondingly; cutting time of joints made of medium density fiberboard (MDF) were $3.6 \%$ to $10.2 \%$ less compared to those of plywood whereas they provided $1.2 \%$ to $5.1 \%$ higher yield excluding Mickey Mouse Ear (MME) (-1.7\%) and Blind Puzzle Lock (B-PL) (-1.8\%) joints. Moreover, average DFMA compliance scores were 7.85 and 7.28 out of 10 for joints made of plywood and MDF, respectively.

2. Joints made of plywood had higher strength properties compared to those of MDF owing to its higher internal bonding strength and mechanical properties. Therefore, joints made of plywood are recommended to utilize in furniture structure where higher strength values are required; in epitome, frames of sofas, etc. On the other hand, joints made of MDF could be used in furniture or cabinet structure where light-duty load and light structure are required such as cabinet doors.

3. Bending moment capacity in compression test results for joints made of both plywood and MDF were higher than those of tension with exceptions for Blind Mickey Mouse Ear (B-MME) and snap (S) joints, for which compression and tension strength values were reasonably close to each other. Joint types lacking self-locking system provided less strength in tension. Therefore, these type joints should not be used in furniture structure where imposed strength exceeds their strength whenever the joint are subject to tension load.

4. A load capacity analysis revealed that $\mathrm{CNC}$ router-cut joints made of both plywood and MDF provided better or reasonably close strength values when compared to those of traditional joints. This was, especially in compression tests, due to complex joint geometry. Therefore, it could be preferred to utilize CNC-cut router joints in furniture 
structure where compression load is primary concern. On the other hand, for the cases where furniture joints are to resist tension load, B-MME and S type joints made of plywood should be used because they were able to provide higher strength values compared to traditional joints.

5. Reduced manufacturing time and increased yield performance could help companies save money if DFMA principles are methodically implemented. In conclusion, although joints made of MDF provided faster cutting time and higher yield compared to those of plywood, they were not as efficient as their counterparts made of plywood in terms of DFMA compliance score and strength in both compression and tension. Therefore, requirements of different furniture structures should be well considered before reaching to a final decision on which joint and raw material type to utilize.

\section{ACKNOWLEDGEMENTS}

This study was supported by the USDA National Institute of Food and Agriculture,

Forest Service, Ministry of National Education of the Republic of Turkey, and the Wood Research Laboratory at Purdue University (West Lafayette, IN, USA).

\section{REFERENCES CITED}

Akturk, M. S., and Ilhan, T. (2011). "Single CNC machine scheduling with controllable processing times to minimize total weighted tardiness," Computers and Operations Research 38(4), 771-781. DOI: 10.1016/j.cor.2010.09.004

Anastas, H. (2007). Experimental Evaluation of Manufacturing Parameters on the Structural Performance of Rounded Dovetail Connections, Master's Thesis, The University of British Colombia, Vancouver, Canada.

Arnette, A. N., Brewer, B. L., and Choal, T. (2014). "Design for sustainability (DFS): The intersection of supply chain and environment," Journal of Cleaner Production 83, 374-390. DOI: 10.1016/j.jclepro.2014.07.021

Ashley, S. (1995). "Cutting cost and time with DFMA," Mechanical Eng. 117(3), 74-77.

Barbosa, G. F., and Carvalho, J. (2013). "Design for manufacturing and assembly methodology applied to aircrafts design and manufacturing," IFAC Proceedings Volumes 46(7), 116-121. DOI: 10.3182/20130522-3-BR-4036.00044

Barbosa, G. F., and Carvalho, J. (2014). "Guideline tool based on design for manufacturing and assembly (DFMA) methodology for application on design and manufacturing of aircrafts," Journal of the Brazilian Society of Mechanical Sciences and Engineering 36(3), 605-614. DOI: 10.1007/s40430-013-0103-1

Bayoumi, A. M. E. (2000). "Design for manufacture and assembly (DFMA): Concepts, benefits and applications," Current Advances in Mechanical Engineering Design and Production 7, 501-510.

Blanchard, B. S., and Fabrycky, W. J (2010). System Engineering and Analysis, $5^{\text {th }}$ Ed., Pearson, London, UK.

Blank, L. T., and Tarquin, A. J. (2007). Basics of Engineering Economy, McGraw Hill, New York, NY, USA.

Boothroyd, G. (1994). "Product design for manufacture and assembly," Computer-Aided 
Design 26(7), 505-520. DOI: 10.1016/0010-4485(94)90082-5

Boothroyd, G. (2005). Assembly Automation and Product Design, $2^{\text {nd }}$ Ed., CRC Press, Boca Raton, USA.

Boothroyd, G., Dewhurst, P., and Knight, W. A. (2010). Product Design for Manufacture and Assembly, $3^{\text {rd }}$ Ed., CRC Press, Boca Raton, USA.

Chang, T. C., Wysk, R. A., and Wang, H. P. (2006). Computer-Aided Manufacturing, $3^{\text {rd }}$ Ed., Prentice Hall, Inc., Upper Saddle River, USA.

Cheng, Q., Zhang, Z., Zhang, G., Gu, P., and Cai, L. (2015). “Geometry accuracy allocation for multi-axis CNC machine tools based on sensitivity analysis and reliability theory," Journal of Mechanical Engineering Science 229(6), 1134-1149. DOI: $10.1177 / 0954406214542491$

Davis, N. R. (2006). Design of a CNC Routed Sheet Good Chair, Bachelor of Science, Massachusetts Institute of Technology, Boston, USA.

Demeter, K., and Matyusz, Z. (2011). "The impact of lean practices on inventory turnover," International Journal of Production Economics 133(2), 154-163. DOI: 10.1016/j.ijpe.2009.10.031

Eckelman, C. A. (2003). Textbook of Product Engineering and Strength Design of Furniture, Purdue University, West Lafayette, USA.

Eckelman, C. A., Erdil, Y. Z., and Zhang, J. (2002). "Withdrawal and bending strength of dowel joints constructed of plywood and oriented strandboard," Forest Products Journal 52(9), 66-74.

Eckelman, C. A., Uysal, M., and Haviarova, E. (2016), "Statistical lower tolerance limits for rectangular mortise and tenon joints," BioResources 11(3), 7162-7171. DOI: 10.15376/biores.11.3.7162-7171

Emmatty, F. T., and Sarmah, S. P. (2012). "Modular product development through platform based design and DFMA," Journal of Engineering Design 23(9), 696-714. DOI: 10.1080/09544828.2011.653330

Erdil, Y. Z., Kasal, A., and Eckelman, C. A. (2005). "Bending moment capacity of rectangular mortise and tenon furniture joints," Forest Products J. 55(12), 209-213.

Forest Products Laboratory (2010). Wood Handbook: Wood as an Engineering Material (Centennial Edition) (FPL-GTR-190), U.S. Department of Agriculture, Forest Products Laboratory, Madison, WI, USA.

Gros, J. (2001). "Furniture industry has to reconsider all products - call it customization design," in: Proceeding of World Congress on Mass Customization and Personalization, Hong Kong, China, pp. 1-8.

Hofer, C., Eroglu, C., and Hofer, A. R. (2012). "The effect of lean production on financial performance: The mediating role of inventory leanness," International Journal of Production Economics 138(2), 242-253. DOI: 10.1016/j.ijpe.2012.03.025

Kamrani, A. K., and Nasr, E. A. (2010). Engineering Design and Rapid Prototyping, Springer, New York, USA.

Kumar, S., Vichare, P., Nassehi, A., Dhokia, V. G., and Newman, S. T. (2009). "Design and implementation of machine tool static error feedback model," in: Proceedings of 2009 IEEE International Conference on Industrial Engineering and Engineering Management, Hong Kong, China, pp. 660-664. DOI: 10.1109/IEEM.2009.5373246

Lefever, D. D., and Wood, K. L. (1996). "Design for assembly techniques in reverse engineering and redesign," in: Proceedings of ASME Design Theory and Methodology Conference, Chicago, IL, USA. 
Liu, D. (2015). System Engineering: Design Principles and Models, CRS Press, Boca Raton, USA.

Meeker, D. G., and Rousmaniere, A. (1996). "DFMA and its role in the integrated product development process," Massachusetts Institute of Technology, (http://web.mit.edu/meeker/Public/DFMAandIPDP.pdf), Accessed 9 Nov 2018.

Pang, S., Oh, J., Park, J., Park, C., and Lee, J. (2011). "Moment carrying capacity of dovetailed mortise and tenon joints with or without beam shoulder," Journal of Structural Engineering 137(7), 785-789. DOI: 10.1061/(ASCE)ST.1943541X.0000323

Rathke, J., Sinn, G., Konnerth, J., and Muller, U. (2012). "Strain measurement within fiber boards. Part I: Inhomogeneous strain distribution within medium density fiberboards (MDF) loaded perpendicularly to the plane of the board," Materials 5(6), 1115-1124. DOI: $10.3390 / \mathrm{ma} 5061115$

Simek, M., and Vaclav, S. (2010). "Traditional furniture joinery from the point of view of advanced technologies," in: Proceedings of the $53^{\text {rd }}$ International Convention of Society of Wood Science and Technology and United Nations Economic Commission for Europe, Geneva, Switzerland, pp. 11-14.

Smardzewski, J. (2009). "The reliability of joints and cabinet furniture," Wood Research 54(1), 1-10.

Snow, M., Asiz, A., Chen, Z., and Chui, Y. H. (2006). "North American practices for connection in wood construction," Progress in Structural Engineering and Materials 8(2), 39-48. DOI: 10.1002/pse.212

Stank, T., Autry, C., Bell, J., Gilgor, D., Peterson, K., Dittman, P., Moon, M., Tate, W., and Bradley, R. (2013). "Game changing trends in supply chain," Ernst \& Young Global Limited, (http://www.ey.com/Publication/vwLUAssets/Game-

Changing_Trends_in_Supply_Chain/\$FILE/UT Game Changing Trends in SC_FINAL Online.pdf), Accessed 9 Nov 2018.

Stienstra, D. (2016). "Introduction to design for (cost effective) assembly and manufacturing," Department of Mechanical Engineering, Rose-Hulman Institute of Technology, Terre Haute, USA.

Suzuki, S., and Miyagawa, H. (2003). "Effect of element type on the internal bonding quality of wood-based panels determined by three methods," Journal of Wood Science 49(6), 513-518. DOI: 10.1007/s10086-002-0513-7

Tamke, M., Thomsen, M. R., and Riiber, J. (2008). "Complex geometries in wood," in: Proceedings of Advances in Architectural Geometry, Vienna, Austria, pp. 65-68.

Tannert, T., Prion, H. G. L., and Lam, F. (2007). "Structural performance of rounded dovetail connections under different loading conditions," Canadian Journal of Civil Engineering 34(12), 1600-1605. DOI: 10.1139/L07-076

Tannert, T., Schmidt, D., and Lam, F. (2008). "CNC timber processing in research and teaching," in: Proceedings of the $51^{\text {st }}$ International Convention of Society of Wood Science and Technology, Concepcion, Chile, pp. 1-9.

Whitten, J. L., Bentley, L. D., and Dittman, K. C. (2001). System Analysis and Design Methods, $5^{\text {th }}$ Ed., McGraw Hill, New York, NY, USA.

Article submitted: Oct. 28, 2018; Peer review completed: January 1, 2019; Revised version received and accepted: January 3, 2019; Published: January 10, 2019.

DOI: $10.15376 /$ biores.14.1.1525-1544 